\title{
Preliminary Study on the Formulation of Syariah Compliant Generic Sustained Release Gliclazide Tablet Using Xanthan Gum
}

\author{
Nik Mohamad Lukman Mat Zin ${ }^{1}$, Anis Syazwani Abd Mubin ${ }^{1}$, Mohamed Sufian Mohd Nawi ${ }^{1}$, Abul Bashar \\ Mohammed Helaluddin ${ }^{1}$, Abdul Razak Kasmuri ${ }^{1}$, Uttam Kumar Mandal ${ }^{2}$ \\ ${ }^{1}$ Kuliyyah of Pharmacy, International Islamic University Malaysia Kuantan. \\ ${ }^{2}$ Department of Pharmacy, Maharaja Ranjit Singh Punjab Technical University (MRSPTU), Bathinda, India
}

\begin{abstract}
Gliclazide (1-(3,3a,4,5,6,6a-hexahydro-1H-cyclopenta[c]pyrrol-2-yl)-3-(4-methylphenyl)sulfonylurea) is a second-generation sulfonylurea which is orally administered in the treatment of non-insulin-dependent diabetes mellitus in adults. Sustain release drugs help to improve drugs bioavailability by controlling the time of drug release or prolonging it. We are reporting the preliminary formulation of sustain release gliclazide tablets with careful choice of all the ingredients and processes related to syariah compliance manufacturing of pharmaceutical products. In this work, xanthan gum, a natural gum was used to achieve the sustain release criteria. The tablets were produced by wet granulation and semi-automatic tableting process. Tablet characterisation was done following the British Pharmacopoeia (BP) criteria. We expect that the outcome of our study will result in a suitable formulation that could be useful for the formulation of such product that will be helpful for the Muslim patient especially during the fasting month.
\end{abstract}

KEYWORDS: Gliclazide, halal tablet, syariah compliance, sustain release, xanthan gum, natural polymer

\section{INTRODUCTION}

Gliclazide(1-(3,3a,4,5,6,6a-hexahydro-1H-cyclopenta [c]pyrrol-2-yl)-3-(4-methylphenyl) sulfony urea) is widely used as antidiabetic. It is a second-generation sulfonylurea which is orally administered in the treatment of non-insulin-dependent diabetes mellitus in adults when dietary measures, physical exercise and weight loss alone are not sufficient to control blood glucose. It has a duration of action of 12 hours or more. It is readily absorbed from the gastro-intestinal tract and extensively metabolized in the liver by hydroxylation, $\mathrm{N}$-oxidation and oxidation to a number of inactive metabolites. Approximately $60-70 \%$ of a dose is excreted in the urine with less than $5 \%$ as unchanged drug. Approximately $10-20 \%$ of the dose is eliminated in the faeces as metabolites. It is protein human plasma bound with plasma half-life of 6-14 hours. ${ }^{1}$

Sulfonylureas were believed to be unsuitable for use during fasting because of the inherent risk of hypoglycemia. Use of chlorpropamide is absolutely contraindicated during fasting because of the high possibility of prolonged and unpredictable hypoglycemia. However, a newer member of the sulfonylurea family such as gliclazide modified

Corresponding author:

Mohamed Sufian Mohd Nawi

Kuliyyah of Pharmacy,

International Islamic University,

Jalan Sultan Ahmad Shah,

25200 Kuantan,

Pahang, Malaysia

Email: msufian@iium.edu.my release has been shown to be effective, resulting in a lower risk of hypoglycaemia. ${ }^{2}$

Gliclazide is less soluble in water but it is well absorbed from the gastro-intestinal tract. The remaining of gliclazide in gastro-intestinal tract should be prolonged by applying it in controlled release form. Several formulations were applied to fulfil this criteria such as floating tablets of gliclazide using HPMC K100M, HPMC K4M and carbopol $934 \mathrm{P},{ }^{3}$ (microencapsulation using natural polymers. ${ }^{4}$ and sustained release gliclazide by wet granulation using hydroxy propyl methyl cellulose, hydroxy propyl cellulose and their combination as polymers. ${ }^{5}$ The brand medicines for gliclazide modified release ready in the market are Diamicron $\circledast 60 \mathrm{mg}$ MR and Diamicron $\circledast 30 \mathrm{mg}$ MR by Servier Laboratories Limited, Ireland.

Syariah compliance in pharmaceuticals requires all manufacturing raw materials be free from prohibited (non-Halal) sources. Besides, processes related to syariah compliance manufacturing of pharmaceutical products should also be implemented. ${ }^{6}$ The aim of this study is to formulate a syariah compliance gliclazide tablet that is suitable to work in stages and also to develop analytical method for quantitative analysis of gliclazide tablet produced. In formulation stage, xanthan gum was used to control the drug release because it is a "halal" natural polymer. An HPLC method was used to detect the presence of gliclazide in the dosage form. In this paper, we are reporting the preliminary findings of the physical characteristics of the tablet that has been produced 
in our laboratory.

\section{Instrument}

Throughout the experiment, an oven (Memmert UM400, Germany), a moisture balance (Mettler Toledo HR83-P, Switzerland), a $4 \mathrm{~mm}$ test sieve (Retsch, Germany), a $1 \mathrm{~mm}$ test sieve (Fisher Scientific Company, USA), a rotary tablet press machine (Rimek Mini Press 2, India), a micropipette (Eppendorf Research, Germany), an analytical balance (Mettler Toledo AX205 Delta Range, Switzerland), a manual tablet testing machine (Pharmatest PTB 311E, Germany), an electronic balance (Ohaus Adventurer AR3130, USA), a friability tester machine (SOTAX Friability Tester F2 CH-4123, Switzerland), Whatman ${ }^{\circledR} 0.45 \mu \mathrm{m}$ membrane filters and an Agilent 1100 Series HPLC System (USA) were used.

Besides, glasswares of suitable grade were also used throughout the production and the quality assessment of the tablets.

\section{MATERIALS}

Industrial grade gliclazide, xantham gum, lactose, polyvinylpyrrolidone K30 (PVP K30), magnesium stearate and talcum were purchased from IKOP Sdn. Bhd., Kulliyyah of Pharmacy, International Islamic University of Malaysia, which fulfilled the requirement for syariah compliance.

For HPLC, acetonitrile (ACN) of isocratic HPLC grade was purchased from Scharlab, Spain while triethylamine (TEA) and phosphoric acid, both of HPLC grade were purchased from Fisher Scientific, United Kingdom. The ultra-pure (UP) water used was obtained from the water purification system (Human Coproration NEX Power 4000, South Korea).

\section{METHODS}

\section{Preparation of tablets}

Fifteen grams of gliclazide, $12.5 \mathrm{~g}$ of xanthan gum and $45.0 \mathrm{~g}$ of lactose were thoroughly mixed using mortar and pestle by following the trituration method. The binding solution was prepared by dissolving $2.5 \mathrm{~g}$ of PVP K30 in $10 \mathrm{ml}$ distilled water. Then, $6 \mathrm{ml}$ of the binding solution was added into the powder portion by portion using a micropipette (Eppendorf Research, Germany) while thoroughly mixed to form a dough. The dough was forced through a $4 \mathrm{~mm}$ sieve to produce wet granules. The wet granules were dried at $50^{\circ} \mathrm{C}$ for 2 hours in an oven (Memmert UM400, Germany). The granules were tested for their moisture content using a moisture balance (Mettler Toledo HR83-P, Switzerland) before and during the drying process and the drying process ended when the moisture content was $3 \%$. The dried granules were then forced through a 1 $\mathrm{mm}$ sieve to break the aggregates. Magnesium stearate and talcum powder $(0.5 \mathrm{~g}$ each) were added and thoroughly mixed to the dry granules as the lubricant and glidant respectively. The mixture was manually weighted for portions of $300 \mathrm{mg}$ in separate weighing boats for the tableting process. Finally, the tablet granules were compressed using a rotary tablet press machine (Rimek Mini Press 2, India). The tablets were stored in a screw capped glass bottle.

\section{Weight variation test}

Twenty tablets were taken randomly and weighted using an analytical balance (Mettler Toledo AX205 Delta Range, Switzerland). Average mass of the tablets was calculated. The percentage of deviation of the weight of individual tablet from the average weight was calculated using equation 1 . The deviation of individual weight from the average weight should not exceed $5 \%{ }^{7}$

The formula used to calculate the deviation was:

Deviation $\frac{\text { [Average weigth-weight of tablet)| }}{\text { Average weight }}(\%)=\times 100$
Equation 1

\section{Tablet hardness}

Hardness test was conducted using a manual tablet testing machine (Pharmatest PTB 311E, Germany) . The tablets were placed between the jaws of the machine. Ten tablets were used for this test and all fragments of tablets were removed before each determination. ${ }^{8}$ The results were expressed as the mean, minimum and maximum values of the force measured. ${ }^{9}$

\section{Friability test}

Twenty two tablets were randomly chosen and carefully dedusted. All of the tablets were weighted using the electronic balance (Ohaus Adventurer AR3130, USA) and the data was recorded. All of the tablets were loaded into the drum of a friability tester machine (SOTAX Friability Tester F2 CH-4123, Switzerland). The drum was set to rotate for 100 times. After being removed from the drum, the tablets were carefully dedusted and weighted once again to measure weight loss from the test. ${ }^{10}$

\section{Assay of gliclazide tablet}

The presence of the gliclazide in the tablets were determined by a high-performance liquid chromatography technique (HPLC) adopted from British Pharmacopoeia 2015. Gliclazide standard solution was prepared by dissolving $40 \mathrm{mg}$ of gliclazide in $10 \mathrm{ml}$ acetonitrile $(\mathrm{ACN})$. The solution was diluted 20 times with a mixture of 2 volumes of $\mathrm{ACN}$ and 3 volumes of ultra-pure water. One $\mathrm{ml}$ of the diluted solution was filtered using Whatman ${ }^{\circledR}$ $0.45 \mu \mathrm{m}$ membrane filter before storing into an HPLC vial. 
For the gliclazide tablet sample preparation, 20 tablets were weighted using an analytical balance (Mettler Toledo AX205 Delta Range, Switzerland) and crushed into fine powder using mortar and pestle. One gram of the tablet powder was shaken for an hour with $50 \mathrm{ml} \mathrm{ACN}$ in $50 \mathrm{ml}$ Eppendorf Tube $^{\circledR}$ and filtered using a Whatman ${ }^{\circledR}$ filter paper grade 1 . The filtrate was diluted 20 times with a mixture of 2 volumes of $\mathrm{ACN}$ and 3 volumes of ultrapure water. One $\mathrm{ml}$ of the diluted sample solution was filtered using Whatman ${ }^{\circledR} 0.45 \mu \mathrm{m}$ filter and stored in an HPLC vial. The HPLC analysis method was carried out using the Agilent 1100 Series HPLC System (USA) with a diode array detector (DAD) as the detector. The mobile phases used were triethylamine (TEA) and ACN in the ratio of 43:57 respectively. The column used was Agilent Eclipse Plus C18 column (USA). The UV wavelength detector was set to $229 \mathrm{~nm}$ and the flow rate was set to 1.00 $\mathrm{ml}$ per minute.

\section{RESULTS AND DISCUSSION}

Preparation of tablets

The components of the tablet and their composition are listed in Table I.
Table I: Components of the proposed gliclazide tablet

\begin{tabular}{l|c}
\hline Name & Amount per tablet $(\mathbf{m g})$ \\
\hline Gliclazide & 60 \\
PVP K30 & 6 \\
Xanthan Gum & 50 \\
Lactose & 180 \\
Magnesium Stearate & 2 \\
Talcum powder & 2 \\
Total & 300 \\
\hline
\end{tabular}

\section{Physical properties of tablets}

The individual and the average weight of the 20 tablets are shown in Table II. The average weight of a tablet is $303 \mathrm{mg}$ with none of the tablet deviating more than $5 \%$ from the average weight. The resistance to crushing (hardness) of the tablets was within $62.4 \mathrm{~N}$ to $87.2 \mathrm{~N}$ with the mean value of $74.02 \mathrm{~N}$ (Table III). The weight loss from the friability test was less than $0.4 \%$. This result indicated that the tablets met the specification by British Pharmacopoeia 2015. .,9.10 $^{-10}$

Table II: Individual weight of 20 tablets.

\begin{tabular}{lllllllllll}
\hline Tablet number & $\mathbf{1}$ & $\mathbf{2}$ & $\mathbf{3}$ & $\mathbf{4}$ & $\mathbf{5}$ & $\mathbf{6}$ & $\mathbf{7}$ & $\mathbf{8}$ & $\mathbf{9}$ & $\mathbf{1 0}$ \\
\hline $\begin{array}{l}\text { Weight (g) } \\
\begin{array}{l}\text { Deviation } \\
\text { mean (\%) }\end{array}\end{array}$ & 0.301 & 0.301 & 0.305 & 0.300 & 0.303 & 0.305 & 0.306 & 0.299 & 0.305 & 0.301 \\
\hline & 0.66 & 0.66 & 0.66 & 0.99 & 0 & 0.66 & 0.99 & 1.32 & 0.66 & 0.66 \\
\hline Tablet number & $\mathbf{1 1}$ & $\mathbf{1 2}$ & $\mathbf{1 3}$ & $\mathbf{1 4}$ & $\mathbf{1 5}$ & $\mathbf{1 6}$ & $\mathbf{1 7}$ & $\mathbf{1 8}$ & $\mathbf{1 9}$ & $\mathbf{2 0}$ \\
\hline $\begin{array}{l}\text { Weight (g) } \\
\begin{array}{l}\text { Deviation } \\
\text { mean (\%) }\end{array}\end{array}$ & 0.303 & 0.307 & 0.300 & 0.302 & 0.302 & 0.301 & 0.299 & 0.301 & 0.304 & 0.308 \\
\hline
\end{tabular}

Table III: Hardness for 10 tablets.

\begin{tabular}{lccccccccccc}
\hline Tablet number & $\mathbf{1}$ & $\mathbf{2}$ & $\mathbf{3}$ & $\mathbf{4}$ & $\mathbf{5}$ & $\mathbf{6}$ & $\mathbf{7}$ & $\mathbf{8}$ & $\mathbf{9}$ & $\mathbf{1 0}$ & Mean \\
\hline & & & & & & & & & & & \\
Hardness (N) & 72.0 & 62.4 & 78.2 & 74.7 & 69.7 & 74.1 & 71.6 & 87.2 & 79.6 & 70.7 & 74.02 \\
\hline
\end{tabular}

\section{Assay of gliclazide tablet}

Figure 1: HPLC-DAD chromatograms of the gliclazide standard, gliclazide sample, blank and placebo.

Figure 1 shows the overlaid chromatograms of the gliclazide standard, gliclazide tablet, blank and placebo. The figure shows the presence of a peak at $\min =3.917$ for both gliclazide standard and gliclazide sample. This indicates the presence of gliclazide in the tablet. However, the quantitative result is not reported here. The method optimisation for quantitative analysis of gliclazide in our new formulated tablets using HPLC is in progress.
Xanthan gum is a potential release-retarding material in the formulation of halal sustained release gliclazide tablet by wet granulation technique. Nevertheless, release profile and quantitative content of gliclazide studies of these tablets should be conducted before further improvement to the tablet formulation could be performed.

\section{ACKNOWLEDGEMENT}

Authors extend their gratitude towards the academic and technical staff of Kulliyyah Pharmacy, IIUM. They are also grateful to the Research Management Centre IIUM for their assistance and support through the grant RIGS 15-090-0090. 


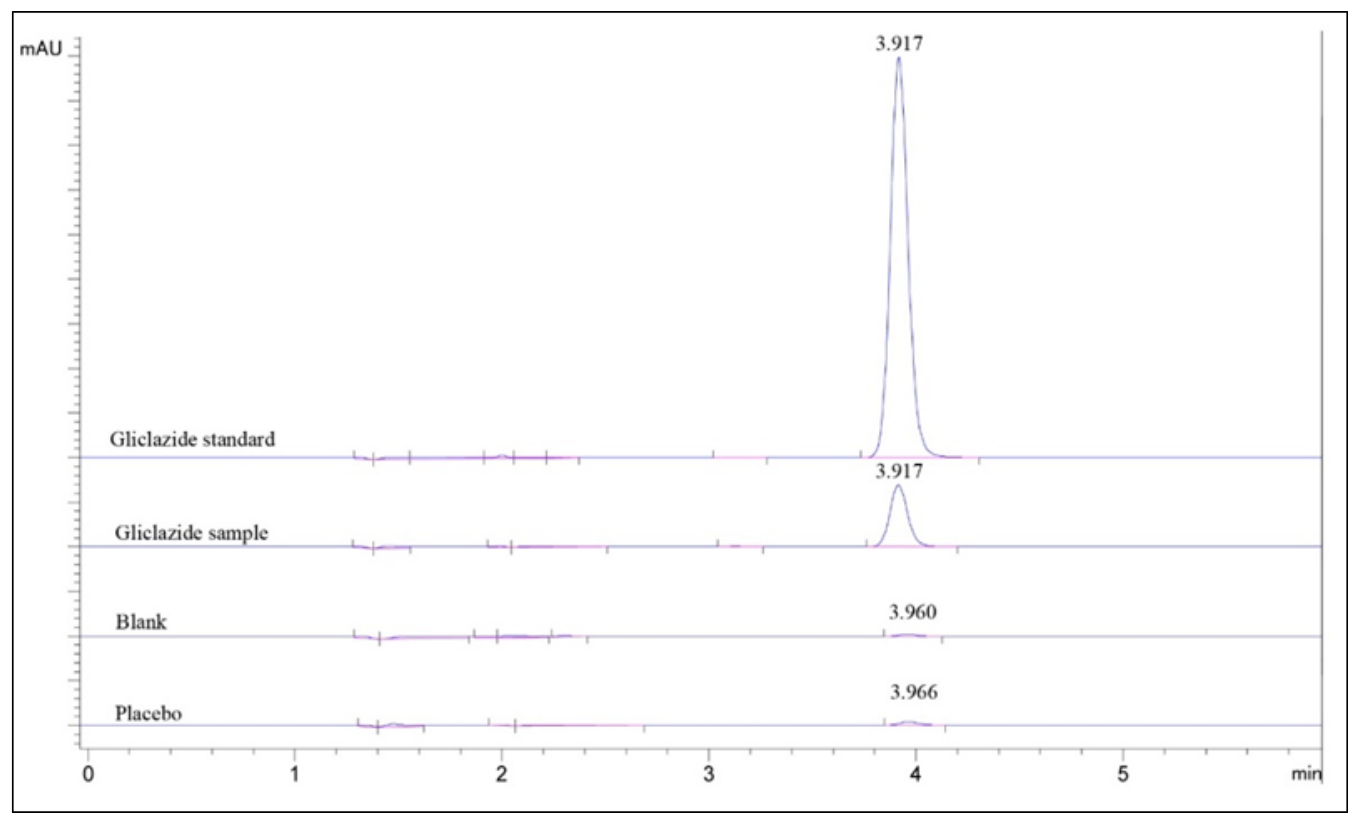

\section{REFERENCES}

1. Xu H, Williams KM, Liauw WS, et al. Effects of St John's wort and CYP2C9 genotype on the pharmacokinetics and pharmacodynamics of gliclazide. British Journal of Pharmacology. 2008; 153: 1579-1586.

2. Schernthaner G, Grimaldi A, Di Mario U, et al. GuideUIDE study: double-blind comparison of once-daily gliclazide MR and glimepiride in type 2 diabetic patients. Eur J Clin Invest. 2004; 34: 535-542.

3. Chowdary K, Hussainy SA. Formulation and evaluation of floating tablets of gliclazide employing HPMC and carbopol. Int J Chem Sci. 2012; 10: 1213-1220.

4. Kumar MS, Ramakrishna R, Kumar NN. Design and development of oral controlled release formulations of gliclazide using natural polymers. IRJP. 2010; 1: 233-242.

5. Panchal VN, Paul DRBN, Dana S, Jadhav R. Formulation and evaluation of sustained release matrix tablets of gliclazide. J Pharm Res. 2011; 4: 4476-4478.
6. Mohamed F. Islamic perspective on manufacturing of pharmaceuticals. In: Ahmad K, ed.. In: Ahmad K, eds. Manufacturing of Halal Pharmaceutical. Kuala Lumpur: . Kuala Lumpur: IIUM Press, 2015: 1 - 33.

7. British Pharmacopoeia Commission. Appendix XII C: Consistency of Formulated Preparations. In: British Pharmacopoeia Commission, British Pharmacopoeia 2015. London: TSO, 2015: 371.

8. Elsayed TM, Mandal UK, Kasmuri A. Development of gliclazide $60 \mathrm{mg}$ modified release tablets using central composite design. Lat Am J Pharm. 2015; 34: 1516-1525.

9. British Pharmacopoeia Commission. Appendix XVII H: Resistance to Crushing of Tablets. In: British Pharmacopoeia Commission, British Pharmacopoeia 2015. London: TSO, 2015: 513.

10. British Pharmacopoeia Commission. Appendix XVII G: Friability. In: British Pharmacopoeia Commission, British Pharmacopoeia 2015. London: TSO, 2015: 510-511. 